\title{
Patient-Related Factors Influencing Adherence to ART, A Case of Chivuna, Southern Province of Zambia
}

\author{
Harriet Ntalasha ${ }^{1}$, Jacob R. S. Malungo ${ }^{1}$, Sonja Merten ${ }^{2}$, Annie N. Phiri ${ }^{1}$, Simona J. Simona1 \\ ${ }^{1}$ The University of Zambia, School of Humanities and Social Sciences, Lusaka, Zambia \\ ${ }^{2}$ Swiss Tropical and Public Health Institute, Department of Epidemiology \& Public Health, Socinstrasse, Basel, \\ Switzerland \\ Email: harriet.ntalasha@unza.zm
}

How to cite this paper: Ntalasha, H., Malungo, J.R.S., Merten, S., Phiri, A.N. and Simona, S.J. (2019) Patient-Related Factors Influencing Adherence to ART, A Case of Chivuna, Southern Province of Zambia. World Journal of AIDS, 9, 49-69. https://doi.org/10.4236/wja.2019.92005

Received: April 24, 2019

Accepted: May 31, 2019

Published: June 3, 2019

Copyright () 2019 by author(s) and Scientific Research Publishing Inc. This work is licensed under the Creative Commons Attribution International License (CC BY 4.0).

http://creativecommons.org/licenses/by/4.0/

\begin{abstract}
Despite the roll out of free life prolonging HIV and AIDS drugs in many public clinics in Zambia and the well documented effects of Anti Retrovirals (ARVs) in reducing mortality among people living with HIV, some people living with HIV still abandon treatment. This study explores patient-related factors that influence adherence to the life prolonging drugs. It is hoped that such information would be useful in enhancing adherence so as to achieve the goal of ART. This information is critical considering irrefutable evidence that non-adherence to Anti-Retroviral Therapy (ART) can lead to drug resistance and consequently, transmission of drug resistant HIV. Drug resistant HIV is not only expensive to handle, but can lead to increased morbidity, mortality and increased incidence of HIV cases particularly, for a low income country like Zambia. Methods: This paper uses data from a large mixed method study which was conducted in a rural setting. The study explored how patient-related factors influence people living with HIV in continuing taking of medication. The paper, therefore, discusses the major reasons reported by HIV infected people on ART for either being able to consistently take their medication or failing to do so. Results: Both limiting and facilitating factors were identified as influencing adherence. Among the facilitators identified were one having a reminder, feeling better after being on ART, seeing someone on ART recover, desire to live longer and disclosure of one's positive status. The limiting factors included forgetting to take medication, non-recovery while on treatment for some time and drug fatigue. A significant association was found between adherence treatment and one having a reminder, desire to live longer and seeing someone on ART get better. Conclusion: While facilitators enhanced adherence, the barriers prevented or discouraged people on ART
\end{abstract}


from continuing taking AIDS medicines as prescribed by their health care providers. In order to avoid drug resistance and other public health implications, such as transmission of drug resistant HIV virus and deaths, there is need to address these patient-related barriers.

\section{Keywords}

Zambia, HIV and AIDS, Patient-Related Factors, Adherence to ART

\section{Introduction}

In Zambia, Antiretroviral Therapy (ART) has been provided free of charge in most of the public health facilities located in both urban and rural areas for more than ten years. Additionally, there is irrefutable evidence that ART does prolong life [1]. Despite all this, however, available evidence shows that some people still abandon treatment, running the risk of developing drug resistance and negative health outcomes [1] [2]. Several studies from elsewhere and within the region have explored factors influencing adherence from the patient's environment such as the health facility, community, structural and medicines. For instance, while some of these studies raise issues related to the way the health care system is organised, such as inadequacies in the health facility including shortage of staff, lack of confidentiality and trust among health care providers, distance to health care centres and related costs, long waiting times and stock outs of AIDS medicines to mention but a few [3] [4] [5] [6]. The other concerns like food and mistrust of health care providers have also been identified by Mukherjee [7] [8]. Others focus on structural factors, poverty, livelihood insecurity and free provision of ARVs [7] [9].

Studies from diverse settings have reported on HIV and AIDS-related stigma. The studies include from China [10], America [11] [12] [13] [14], Dominican republic [15], and within the subthe region [16] [17] [18]. Some qualitative studies have also observed some patient-related factors such as forgetting [19] [20], seeing someone recover or die while on ART, fear of side effects [21] while [22] expressed medicine related concerns.

While these previous studies provide insights into the various reasons for treatment interruptions, it appears the focus, particularly in Zambia, has been on the environment in which the individual patient exists. These studies lack in-depth exploration of patient-related factors over which an individual patient has control and how these can either facilitate or limit adherence. Additionally, most of the studies identified above were qualitative and so much as they provide insights into these factors, they do not provide measures of levels of influence of the common reasons identified. This study, therefore, explores the behavioural or patient-related reasons that lead an individual living with HIV either to continue or abandon treatment. By providing some statistical measurements of some of the identified reasons, the study gives an idea of levels of 
influence of these reasons and hence gives entry points for future interventions. It is hoped that this information will contribute to improving health outcomes of people living with HIV and also to achieving the overall goal of ART that of viral suppression and healthy living which will eventually lead to reduced morbidity, reduced mortality and less transmission of new cases of HIV. With increased adherence, the possibility of transmitting drug resistant HIV virus will also be minimised [23] [24]. The later can contribute to achieving the vision of zero new infections and zero HIV-related deaths. This is considering that ART is not only the available option for those people that are already living with the virus but one of the most effective tools available and an essential part of efficient sustainable response to AIDS.

\section{Methods}

\subsection{Study Area and Population}

The study was carried out in Chivuna, a rural community located approximately $60 \mathrm{~km}$ South-East of Mazabuka town, $35 \mathrm{~km}$ from the Great North Road and about $70 \mathrm{~km}$ South of Lusaka, the capital city of Zambia. The main ethnic group is the Tonga speaking (or Ba-Tonga in plural), a matrilineal and patrilocal group of people. Chivuna has a population of approximately 19,000 scattered in an area covering about 34 square kilometres. The main source of livelihood is subsistence farming, which is seasonal and dependent on the rainfall pattern. Like most rural areas in Zambia, poverty levels are quite high, averaging more than seven people in ten being poor and having limited access to basic necessities, including food and health. While nearly all the health facilities in the area offered VCT, ART services are only offered at Chivuna and Mbayamusuma health facilities. The two facilities are more than $40 \mathrm{~km}$ apart. A CD4 counting machine that had been provided by an NGO to Chivuna Heath facility was by study time relocated to Chikankata Mission Hospital, a bigger health hospital, located about $50 \mathrm{~km}$ away from Chivuna Health Facility.

\subsection{Data Collection and Analysis}

The data presented here were part of a bigger mixed method though mainly qualitative, ethnographic approach conducted over a period of one and half years between 2010 and 2011, focusing on people's experiences and views related to testing, ART uptake and adherence. The study used a descriptive and exploratory design including qualitative methods such as participant observation, key informant interviews (KIIs) (19), focus group discussions (FGDs) (24), and in-depth interviews (IDI) (67). The study population included both those persons who had been tested for HIV and those that had not tested. The objective was to collect not only people's perceptions but also, and more importantly, their lived experiences. For the quantitative data, an informed questionnaire was used to collect data from respondents. The questionnaire was an informed one because it was designed after the qualitative study. Issues which strongly came 
out from the qualitative aspect of the study were the ones that were further followed up and interrogated in the survey. This means that the questionnaire was not designed by the researcher alone but by the study participants themselves as well. All interviews except for the key informants from the health facility, were conducted in Chitonga (the local language of the area).

To recruit study participants for the qualitative study, there was need to identify specific members of the population with specific information of value to the study. With this in mind, a purposive recruitment strategy was used to identify participants with certain information useful for the study. With this procedure, key informants such as community leaders, traditional healers, leaders of Non-Governmental Organisations (NGOs) and Community Based Organisations (CBOs) were elected. Thereafter, the snowball technique was used whereby, the study participants located first were able to identify the next study participant with characteristics desired for the study. Through this procedure, it was also possible to identify participants such as HIV positive people, ART users and care givers who in turn identified their counter parts. The entry point for the users of VCT and ART services as well as care givers was the ART clinic. Ethical issues were taken into consideration at all stages of the study.

At the health facility level, exist interviews were used by interviewing participants as they were leaving the ART clinic after seeking health services. Some of the interviews were also carried out as the users arrived at the clinic. Respondents/participants were selected as long as they were youths aged between 18 and 24 years, and adults above 25 years living in the study area and willing to be interviewed. However, for the qualitative data, youths aged 15 and 24 years were also included. A total of 67 IDI, 24 FGDs of ten people in each and 19 KIs were conducted.

A multi-stage sampling approach was used to identify communities and respondents at household level. To begin with, stratified random sampling was used to select communities to be included in the study. These were grouped as either near or far away from the health facility. This was to ensure comparing of responses. A total of five communities were selected. Interval systematic random sampling was then used to select households from the household lists out of which 393 households were selected. This was followed a probability proportionate to size sampling strategy (PPS) to select participants from each community. A simple random sampling was employed to select the study participants in cases where more than one eligible person was found in a household. Where only one person was eligible, that particular person was targeted for the interview and appointments were made in cases where no eligible person was present at home. Two hundred and sixty (260) respondents were selected at health facility level using exit interviews bringing the total number of respondents interviewed to 653. This sample size was arrived at using power calculation and the size of the sample selected presented the researchers with a sample size big enough to detect the effects of interests at 95 percent confidence level. 
For the purpose of testing effectiveness, appropriateness, reliability and validity of the research instruments in soliciting for the data required, a pilot study was conducted before embarking on the main study.

For the purpose of quality control, all focus group discussions were moderated by the principal investigator who is fluent in the local language. With permission from the study participants, interviews were also tape recorded and transcriptions were done as soon as possible to avoid any loss of data. All interviews conducted in the local language were transcribed and interpreted into English after which all data were put into a word processing application by version and analysed using ATLAS-TI version 6 using grounded thematic coding, starting with open coding after which all the codes were grouped into similar categories. From these categories, themes were generated. The questionnaire was analysed using SPSS. Ethical approval for the study was obtained from the Research Ethics Committee at the University of Zambia and also cleared by the Ministry of Health. For all the individuals that took part in the study, informed consent was sought and all the identities were anonymous.

\subsection{Study Limitations}

This study was a case study carried out in a rural and peculiar mission setting. This would make the study findings not for generalisation. For comparative purposes, it would have been desirable to select another study site, preferably from another province. However, due to financial constraints, the study was confined to one locality.

Though frantic efforts were made to ensure equal representation of the sample by gender, this proved impossible because generally women were more available for interviews. For instance, while women were usually found at home during the interview period, contacts were made to interview men, but were out for extended periods.

Despite these limitations, the findings from this study were validated and hence consistent with existing literature both locally and globally. Additionally, the size of the sample was big enough to produce representative results.

\section{Findings}

\subsection{Background Characteristics of the Participants}

The tables below illustrate the background and livelihood characteristics of the respondents in the study. Regarding the background information, it can be noted that 25 per of the respondents were aged between 35 years and 39 years. In terms of sex, 27.8 percent of the male respondents were aged between 35 years and 39 years while female respondents 25.8 percent were aged 45 years and above.

In terms of education, the majority of the respondents (63.4 percent) had primary education. In terms of sex differences, the results show that more males (65.9 percent) have primary education compared to females (61.6 percent). Regarding marital status, the results show that 70.9 percent of the respondents were 
married. In terms of distribution by sex, the results show that most males (79.9 percent) were married compared to females (64.5 percent).

Regarding the religious affiliations of the respondents, the results also show that the majority of the respondents were Protestants (at 57.3 percent for Protestants compared with 42.7 percent for Catholics). Religion by sex shows that 58.2 percent of the males were Protestants compared to 56.6 percent of the females.

In terms of the economic and livelihood characteristics, the study found that a substantial number of the respondents, (33.1 percent) were involved in farming using cattle as a source of their livelihood. Further, results by sex show that about 49.3 percent of male respondents were involved in farming using cattle while 36.1 percent of the female respondents were involved in house work (Table 1).

Table 1. Background characteristics of respondents.

\begin{tabular}{|c|c|c|c|c|c|c|}
\hline \multirow{3}{*}{ Age Group } & \multicolumn{6}{|c|}{ Sex } \\
\hline & \multicolumn{2}{|c|}{ Male } & \multicolumn{2}{|c|}{ Female } & \multicolumn{2}{|c|}{ Total } \\
\hline & $\mathbf{N}$ & Percent & $\mathbf{N}$ & Percent & $\mathbf{N}$ & Percent \\
\hline $18-20$ & 2 & 0.7 & 8 & 2.1 & 10 & 1.5 \\
\hline $21-24$ & 39 & 14.3 & 48 & 12.6 & 87 & 13.3 \\
\hline $25-29$ & 33 & 12.1 & 46 & 12.1 & 79 & 12.1 \\
\hline $30-34$ & 33 & 12.1 & 57 & 15.0 & 90 & 13.8 \\
\hline $35-39$ & 76 & 27.8 & 87 & 22.9 & 163 & 25.0 \\
\hline $40-44$ & 27 & 9.9 & 36 & 9.5 & 63 & 9.6 \\
\hline $45+$ & 63 & 23.1 & 98 & 25.8 & 161 & 24.7 \\
\hline Total & 273 & 100.0 & 380 & 100.0 & 653 & 100.0 \\
\hline \multicolumn{7}{|c|}{ Education } \\
\hline Non & 28 & 10.3 & 70 & 18.4 & 98 & 15.0 \\
\hline Primary & 180 & 65.9 & 234 & 61.6 & 414 & 63.4 \\
\hline Secondary & 62 & 22.7 & 71 & 18.7 & 133 & 20.4 \\
\hline Tertiary & 3 & 1.1 & 5 & 1.3 & 8 & 1.2 \\
\hline Total & 273 & 100.0 & 380 & 100.0 & 653 & 100.0 \\
\hline \multicolumn{7}{|c|}{ Marital status } \\
\hline Married & 218 & 79.9 & 245 & 64.5 & 463 & 70.9 \\
\hline Single & 20 & 7.3 & 31 & 8.2 & 51 & 7.8 \\
\hline Divorced/Separated & 13 & 4.8 & 38 & 10.0 & 51 & 7.8 \\
\hline Widowed & 22 & 8.1 & 66 & 17.4 & 88 & 13.5 \\
\hline Total & 273 & 100.0 & 380 & 100.0 & 653 & 100.0 \\
\hline \multicolumn{7}{|c|}{ Religion } \\
\hline Catholic & 114 & 41.8 & 165 & 43.4 & 279 & 42.7 \\
\hline Protestant & 159 & 58.2 & 215 & 56.6 & 374 & 57.3 \\
\hline Total & 273 & 100 & 380 & 100.0 & 653 & 100.0 \\
\hline
\end{tabular}

Source: Field work Chivuna survey 2009-2011. 


\subsection{Patient-Related Factors Influencing Peoples' Adherence to ART}

The study identified both limiting and facilitating factors as influencing adherence. Among the facilitators were; one having a reminder, feeling better after being on ART, seeing someone on ART recover, desire to live longer, disclosure of one's positive status while limiting factors were forgetting, non-recovery while on medication for some time and drug fatigue. These are presented below.

\subsubsection{Having Reminders}

Several factors were identified as positively influencing peoples' adherence to treatment. These included one having a reminder to take medicines. Many respondents reported that having reminders helped them take their medicines every day and on time. Having a reminder meant having someone to remind them to take medicines, such as family members or significant others. Those who had disclosed to their partners mentioned of their spouses as being important reminders with comments like: "Having someone or something to remind you helps a lot in taking medicines."

The results in Table 2 show the role of one having a reminder in adherence that all those people with reminders never missed taking their drugs.

The above findings reflect a very close association between adherence and one having a reminder. Instead of depending only on human reminders, some ART users mentioned physical reminders among which were: Use of wrist watches, setting cell phone alarms and use of radios. However, some respondents complained of having experienced negative reactions from some community members for putting on wrist watches because as narrated during a focus group discussion, "These days whoever wears a wrist watch is associated with ARVs". This was linked to the new type of stigma that was associated with ARVs.

Some clients reported putting medicine bottles in certain positions as noted by a 37-year-old female ART user when she stated that:

Every evening after taking the medicines, I put the bottles on top of the table and after taking the pills every morning, I put the bottle under the table. So depending on where the bottle is, then I know I have already taken or not taken the medicine.

Table 2. The Role of a Reminder in Adherence to ART.

\begin{tabular}{ccccccc}
\hline \multirow{2}{*}{$\begin{array}{c}\text { The Longest Period of Time } \\
\text { Ever Missed Taking ARVs }\end{array}$} & \multicolumn{2}{c}{ Yes } & \multicolumn{3}{c}{ No } & \multicolumn{2}{c}{ Total } \\
\cline { 2 - 7 } & No. & $\%$ & No. & $\%$ & No. & $\%$ \\
\hline 1 - 2 Weeks & 3 & 6 & 2 & 40 & 5 & 100 \\
2 - - 8 Weeks & 28 & 52.8 & 25 & 47.2 & 53 & 100 \\
More than 2 Months & 0 & 0 & 1 & 100 & 1 & 100 \\
Never Missed & 213 & 100 & 0 & 0 & 213 & 100 \\
Total & 244 & $\mathbf{8 9 . 7}$ & $\mathbf{2 8}$ & $\mathbf{1 0 . 3}$ & $\mathbf{2 7 2}$ & 100 \\
\hline
\end{tabular}

Source: Field work, Chivuna survey 2009-2010, Ch2 (3) = 115.980, p-value $=.000$. 
Although many study participants mentioned the value of using a watch/clock, radios and cell phone alarms, because of high poverty levels in the area, a number of study participants explained that they were not able to afford most of these dependable reminders. As a result, some mentioned that they were forced to request a neighbour who owned either a radio or cell phone to tell them when it was time for taking medicines. This in a way led to involuntary disclosure of one's status. Some resorted to using shadows and shades. Concern over use of such time telling devices was that they were unreliable because at times they would be unavailable. For instance, on a cloudy day one would not use shadows to determine time. Also use of radio was not reliable as a radio announcer may be carried away with the presentations and forgotten to announce the time.

\subsubsection{Disclosure of One's Positive Status}

Disclosure of one's status to either close family members and significant others was also reported to be an important facilitator for retention in care and treatment while non-disclosure was a predictor for non-adherence. A number of those who decided to disclose their status stated clearly that they did it as a way of having a reminder to avoid forgetting. Forgetting, particularly in the early stages of treatment, was seen by many clients as a big challenge in taking drugs every day. Additionally, for many of the respondents, disclosure was a form of mobilizing emotional, social and material support which helped reduce worry and stress that came with one knowing that they were living with an incurable disease. Those who had decided to disclose thus, were able to attest to the benefits of disclosing their HIV status to both family members and close associates as illustrated by quotes below:

It [disclosure] has helped me a lot in terms of jobs. There are some hard jobs that I cannot do, so since the family members know about my status they are always willing to help me. The other benefits of informing them about my status are that they remind me to take medicine, more especially my wives. If I am out and it is almost time to take the medicine one of my wives would even follow me with the medicine to wherever I could be so that I can take the medicine at the right time (51-year male polygynous ART user community based IDI).

I should say that having disclosed to my family has really helped a lot, before I did so, I used to feel as if I was carrying something very heavy but after I told them about my status and that I was taking ARVs everything just changed because my family members are very supportive and sometimes we even joke about my status, sometimes when I am almost forgetting you hear of my children shouting, have you already recharged with MTN units? And we laugh about it (43-year-old male ART user, clinic based IDI).

Disclosure is good because even food and transport money your family members and others close to you can assist you if they know about your status but if they do not know, they cannot do it, some even escort their sick to the health facility. Even when we go out visiting we should tell those we are visiting so that 
they know in case of emergency (Elderly man, clinic based men's FGD).

Health care providers and care givers also did acknowledge the role of self-disclosure in ensuring that somebody took medicines accordingly. For instance, a female health care worker reported that people handled a positive result differently, with a possibility of some of them going into depression. She stated that this could lead to treatment interruptions and hence the need for emotional support from family members. She alluded further, to other challenges like forgetting that many clients encountered particularly in the initial stage of their treatment. Therefore, in sharing her experiences she explained that:

I think the other thing is the disclosure of one's HIV status to close family members and other close associates. I have heard of many clients confessing that life became much easier after they told their family members that they were positive and were taking medicines because of the support they received emotionally. You know some people go into depression after being told of their status and they may not be able to take their drugs daily if there is no support and encouragement. They may end up just give up everything and say let me just die. When beloved ones know the status of either a relation or friend there are so many other things that they can do to ensure that one takes the drugs accordingly. This may be lending transport money, providing food, or even travelling to the health facility to collect medicines on behalf of the patient and so forth. Then there is an issue of forgetting. Many clients have told me that they used to forget a lot when they started taking their medicines, but they were always reminded by their family members because they had disclosed to them that they were taking $A R V s$.

It was, however, reported that many people decided to use selective disclosure. This is where a client decides to disclose to some and not others. For instance, many respondents revealed that they disclosed to their close family members, and that within family members they decided to disclose to adults and older children only because these could understand what was going on. One female client reported not disclosing to her aged mother because "she was not strong enough to handle the news" and did not want her to be worried. Within sexual relationships, some women decided not to disclose to their spouses for fear of violence and abandonment. Other respondents also stated that they only selected to disclose to those they knew would keep secrets.

Those who had decided initially not to disclose narrated the disadvantages of non-disclosure as they shared their experiences. For instance, a 40-year-old male ART user narrated how one day, he could not take his drugs because he failed to do so in the presence of his friends who he had not disclosed his status too. $\mathrm{He}$ thus recounted:

I used to miss taking medicines especially in early days when I was still hiding my status. For example, one day when I was with my friends it was time for me to take drugs and then the conversation became so interesting. If my friends had gone to their homed 20 minutes past the time I was supposed to take my drugs, then I would take them but they did not go as expected and by the time they left, 
it was too late. I could not take my medicines in their presence because I did not want them to know (Male ART user on ART for almost 4 years, community based IDI).

There were reports of people who decided not to disclose their status and ended up dying in the process due to lack of encouragement and support. For instance, in one community located about $20 \mathrm{~km}$ west of Chivuna Rural Health facility, a man was reported to have been travelling to Chikankata Mission Hospital which is located approximately $50 \mathrm{~km}$ away for ART instead of Chivuna health facility located nearby. His family members reported that they did not know his status, though they suspected their relative of being on ART, until they discovered what was termed as a big bundle of ARVs under his bed after he died. All the community members were very positive that this could not have happened if he had disclosed his status to his family members because they would have been given him moral support that needed in such a situation.

Some married women strongly pointed out that they were afraid of disclosing their status to their spouses because of possible negative reactions. They reported that non-disclosure of their status to their spouses was what helped them to adhere to medication. They stated that for them to take the drugs they had to hide them to avoid trouble. One woman narrated that she tested first before her husband and only disclosed to a friend in the neighbourhood because she was not sure how her husband would react. She stated that she also had to keep her medicines with the same friend and was only able to disclose to the husband after he tested positive. She explained further that if she had disclosed first, there was a possibility of her being blamed for the infection. Several women who did not disclose their positive status mentioned fear of victimisation, rejection and infidelity accusations as some of the reasons for not doing so.

Asked about disclosure, the majority of the respondents, more than 60 percent stated that they decided not to disclose their status to anyone. Of those who did disclose, about 49 percent disclosed to their partners while the majority 51 percent disclosed to either relative in the household or friends outside the household. The fact that the majority of the people decided not to disclose to their spouses who were supposed to be their closest associates meant depriving themselves of the much-needed support. This also reflected the interpersonal challenges involved with matters relating to HIV and AIDS particularly among sexual partners.

Non-disclosure was attributed to anticipated negative reactions. In fact, a number of those who disclosed their status complained of having experienced negative reactions. Some of the negative reactions experienced by those who disclosed their status are presented in Table 3 below.

These results are a clear indication that stigma and discrimination levels against somebody known to be living with the virus were high.

\subsubsection{Feeling Better}

Feeling better and disappearing of symptoms was reported to be both a driver 
Table 3. The experiences of HIV and AIDS-related stigma and discrimination after disclosure of HIV positive test results.

\begin{tabular}{ccccccc}
\hline & \multicolumn{2}{c}{ Yes } & \multicolumn{2}{c}{ No } & \multicolumn{2}{c}{ Total } \\
\cline { 2 - 7 } & No. & $\%$ & No. & $\%$ & No. & $\%$ \\
\hline Not allowed to touch someone & 99 & 96.1 & 4 & 3.9 & 103 & 100 \\
Asked not to touch some one's child & 101 & 98.1 & 2 & 1.9 & 103 & 100 \\
Blamed & 101 & 98.1 & 2 & 1.9 & 103 & 100 \\
Being avoided & 101 & 98.1 & 2 & 1.9 & 103 & 100 \\
\hline
\end{tabular}

Source: Field work Chivuna survey 2009-2010.

and barrier for adherence. Some of those who had recovered were reported to continue taking their medication as they did not want to fall ill again. They pointed out that they remembered how sick they were before starting ART and felt proud of their good health. They felt good that they were able to work for themselves again instead of depending on other people. Others said the drugs gave them a second chance to work and be able to leave something for their children when they die. Sharing her experiences, a 33-year-old female ART user for three years noted:

After all the side effects stopped, I feel much better now and I would not want to fall sick again and so I make sure I take my medicines accordingly. I have gained weight as well and I am very proud of the way I look and feel. I used to forget but now am proud because I just find reminding myself due to the way I am feeling. I hope to work hard for my children, (Female ART user, clinic based IDI).

Reiterating similar sentiments, another female ART user stated:

I have seen that am now fat and healthy than before I started ART. I am strong and able to work for my family. This encourages me to take my medicines. My mind is also free because I have known the goodness of ART, (56 years old ART female ART user clinic based IDI).

Same views were expressed during focus group discussions as is illustrated by the quotes below:

Also feeling better does encourage a lot, for me I used to have boils all over my body including buttocks but now all that is over and I would want to continue feeling healthy okay (Elderly male, clinic based mixed FGD with ART users).

Not wanting to be sick again, you can imagine you were being brought in a scotch cart and then you start coming to the clinic on your own, you can really think twice to skip your medication,(Female ART user in late twenties, female clinic based FGD).

Some respondents reported that because they were healthy again, they were tempted to discontinue with ARVs as they started doubting whether they were ever suffering from AIDS. For instance, during one of the clinic based IDI, a 40 year male ART user for three years noted:

Ahh sometimes, feeling healthy again can make you stop taking the medi- 
cines, there have been times when I feel and start thinking that maybe it is not really AIDS that was troubling me. Look at me, are there any signs that I was once very ill? I am just following instructions from health care providers that are all because I do not feel any more pain in my body.

These sentiments were reiterated during a mixed focus group discussions with ART clients when one of the male discussants, while being supported by fellow discussants retorted:

Feeling better and thinking that I am healed can make one stop taking medicine. (Elderly male discussant, amid agreement from other discussants, clinic based mixed FGD).

These views were also expressed by some care givers. A 45-year old female, who once had to care for her husband in this sub-section when he was bedridden, for instance, narrated how her husband who had fully recovered was reluctant to take his medicines because he was, "feeling better".

A number of study participants also gave one being too sick, particularly those from remote communities as another factor which made replenishing of drugs difficult. It was further noted that at times one being too sick also made it difficult for one to take the medicines even when they were available, especially those who lacked social support to ensure that they took their medication accordingly.

\subsubsection{Desire to Live Longer}

Desire to care for one's family or children and in particular young children, came up several times as a driver for entry and continued participation along the continuum. Many study participants said that they had seen orphans suffering in the community and they did not want their own children to be found in a similar situation. This is clear from statements below:

Then I want to continue caring for them, since their father is dead who would look after them, this really troubles me, if I die no one would look after them, many orphans are suffering in our communities and I did not want this to happen to my children (Middle-aged widowed mother of 3, community based IDI).

I think being sick or not feeling unwell is what prompted me to go for VCT, another thing was that I was worried about my children because they were still very young. So, I would say to myself, (How can I surely die and leave my children) (37-year-old male ART user, father of 4, clinic based IDI).

It was also common to hear people having gone for testing so as to access care and treatment in order to avoid dying early not necessarily for anybody else but for themselves because they just wanted "to stay alive". Such comments were also common for one's decision to start taking medication and also to consistently and continuously taking medication. So comments like "Life is good, wanting to stay alive and not wanting to die early was also common as a reason for testing". While some did it for their own sake, for others it was because they wanted to live longer for the sake of their families, particularly those with very young children. Others were seeing someone on ART get better. Results are contained in Table 4 below. 
Table 4. Individual reasons facilitating adherence.

\begin{tabular}{|c|c|c|c|c|c|c|c|c|c|c|}
\hline \multirow{3}{*}{$\begin{array}{l}\text { Individual factors } \\
\text { contributing to } \\
\text { adherence }\end{array}$} & \multicolumn{10}{|c|}{ Levels of agreement } \\
\hline & \multicolumn{2}{|c|}{ Very strong } & \multicolumn{2}{|c|}{ Quite strong } & \multicolumn{2}{|c|}{ Somewhat strong } & \multicolumn{2}{|c|}{ Not strong } & \multicolumn{2}{|c|}{ Total } \\
\hline & No & $\%$ & No & $\%$ & No & $\%$ & No & $\%$ & No & $\%$ \\
\hline $\begin{array}{l}\text { Seeing someone } \\
\text { on ART recover }\end{array}$ & 218 & 85.8 & 15 & 5.9 & 20 & 7.9 & 1 & 4 & 254 & 100 \\
\hline $\begin{array}{l}\text { Desire to support } \\
\text { one's family }\end{array}$ & 130 & 51.2 & 123 & 48.4 & 1 & .4 & & & 254 & 100 \\
\hline Desire to live longer & 210 & 82.7 & 22 & 8.7 & 22 & 8.7 & 0 & 0 & 254 & 100 \\
\hline
\end{tabular}

Source: Field work, Chivuna survey 2009-2011, p-value $=0.000$ for all the factors.

The results in the table show that there was a close association between adherence and all the facilitating factors identified indicating that they played an important role in ensuring that people adhered to medication.

\subsection{Barriers}

\subsubsection{Fear of Side Effects}

While positive effects and efficacy of the medicines encouraged people living with HIV to continue taking medication, many of them also complained about what they referred to as terrible side effects from the medicines particularly, in the initial stages. Among the most commonly mentioned side effects were persistent headaches, nausea, heart palpitations, dizziness, swollen legs, diarrheal, vomiting, general body pains, un-proportional increase in body weight (such as big belly, small legs, big neck muscular hands) body rashes, partial blindness and increase hunger and appetite. Others also pointed out that they felt sicker than before starting to take ARVs. The effects included both positive effects and side effects.

Those who experienced these negative effects narrated how they either stopped or tempted to stop taking ARV, to postpone and dread the dosing times because of these "terrible side effects". Many pointed out that they had to be strong to continue" for the sake of feeling well again, and wanting to live longer. Some of these experiences are illustrated by the quotes below:

For me I had so many problems just after starting the medicine, sometimes, I could not open my eyes, sometimes I used to have a terrible headache like my head was splitting into two, even becoming deaf, I do not know whether it was hunger because sometimes I would take them without any food, ah if you are not strong you can give up, but I thought about my children, I would say to myself, who will look after them, their mother is dead, this encouraged me to continue taking the drugs, (Widower father of six young children, the oldest 17 years old and the youngest 8 years old community based IDI).

When I started taking medicines, I felt sicker than before. My body became so weak; I used to feel dizzy after taking the medicines. Sometimes I used to feel and behave like somebody who was drunk with beer because I would fail to find 
the door. I had bad effects from the medicine. So when it was time to take the medicine. I used to think to myself should I take it or I just stop taking this medicine, (46-year-old male ARV user, community based male IDI).

Health care providers and care givers were also cognizant of the difficulty that people on ART had to go through because of side effects as conveyed by the following quotes:

And then there are some clients who develop bad side effects, a number of people just give up, we really have to work hard to encourage them, but again the distances are a problem so some people may not come to seek more information, and so some start thinking what they have been hearing about ARVs being killer drugs is true so they abandon the medicines, (Health care provider).

The only problems I have seen are the side effects, in the beginning he [referring to the husband] used to complain a lot after taking the medicines. He used to have headaches most of the time and he also used to complain about dizziness and I had to force him to take the medicine. (Female care giver cited above, married to an ART client, community based IDI).

A number of ART users and some key informants from health related background reported that the many side effects from ARVs were one of the reasons why some patients opted for traditional medicines as these did not have any side effects.

\subsubsection{Forgetting}

Forgetting was one of the factors that were repeatedly reported as causing ART clients to miss their drugs. Many study participants attested to facing this barrier especially in the initial stages of treatment. During a mixed group discussion, participants were emphatic on forgetting as a barrier to adherence as can be illustrated by the statements below:

Elderly Male: Yes, forgetting is the major problem, especially when you are just starting sometimes you are supposed to take at 8 and you remember at 09:00 hours. I used to forget a lot at the beginning but with time I have become used now.

Middle Aged Male: I think one major problem with the medicines is just forgetting so if it was possible to make them in injection form it would be better. It can also relieve us of the requirement to take drugs every day (in agreement from most of the other participants).

In another interview, a 71 widow also shared her experience when she noted:

Sometimes I do forget taking medicines on time forget on time. By the time I realise that I have not taken medicine it would be two hours or four hours later. I have seen forgetting a problem for adherence (ART user community based IDI).

Some study participants reported of putting measures such as those under reminders to ensure that they did not forget to take medicines. So for instance, some reported of disclosure to say, a family member who would act as a reminder.

A number of key informants and discussants during focus group discussions 
mentioned of too much beer drinking as one of the reasons why some people skipped their doses. Forgetting because of being too busy with other activities, especially those relating to livelihoods, such as looking for food for the family was also raised in some discussions, especially with women discussants. Some study participants also mentioned of not taking their medicines because they had travelled to some distant place without them, or as a result of hoping to get back home early but end up being delayed.

Many study participants who had been taking ARVs also attested that forgetting reduced with time. Other participants said that with time, they had "developed certain feelings" that usually reminded them of not having done something very important. They narrated that, taking medicines became something they did automatically like eating or putting on clothes. Therefore, sharing her experiences a 60-year-old widow who had been on ART for more than three years, elucidated that:

Yes it is there [forgetting] but with time it lessens, taking ARVs becomes like eating like eating or dressing up, you never forget to eat, when it is time to eat you remember or when it is time to dress up you do so, in fact we eat our food almost at the same time every day, immediately it is time to eat you feel the hunger, so it is the same with these medicines, you get used with time. Even with clothes no one ever forgets to put on something when they are going out, they become part of you. For me sometimes I feel heavy and strange, I feel as though there is something I have not done. Then immediately, I remember I have not taken my medicine. (Widowed female ART user, clinic based IDI).

These experiences were reiterated by several other ART users who had also been on treatment for some time as shown by statements below:

Every time it is about time to take the medicine, I hear a bell in my ears reminding me to take the medicine. It is like going to school. Every school girl or boy wakes up early and prepares to go to school on time. They fear of being punished if they are late, same it is in the taking of AIDS medicines, (Man in early thirties on ART user for almost 2 years, mixed clinic base FGD, amid support from other participants).

Yes, the heart beats faster, then you know there is something you have not done, so you know it is your medicine you have not taken (Elderly female, mixed clinic based FGD).

After one was on medication for some time, some participants complained of being tired of taking medication on a daily basis. So being tired of taking medicines or drug fatigue dissuaded some people living with HIV from sticking to medication as discussed below.

\subsubsection{Tired of Taking Medication Every Day}

Though they were very grateful that drugs were available, some of those on medication for some time indicated that they were tired of taking medication every day. "While being on the drug for a long time did help in adherence, at times it also acted as a barrier because of what some participants referred to as 
being tired of taking medicines every day". This was so particularly, when there were no signs of one recovering after being on medication for a long time. Comments like, "We are tired of taking medicines every day." Nachega, J. B., A. R. Knowlton, A. Deluca, J. H. Schoeman, L. Watkinson, A. Efron, R. E. Chaisson, G. Maartens, W. Lippincott \& Wilkins (2006). Adherence to antiretroviral therapy in HIV infected South African adults, stigma, alcohol abuse, lack of financial resources and food and treatment supporters to improve adherence. Acquired Immune Deficiency Syndrome, Volume 43, Supplementary 1, 5127-5132.

These sentiments were quite common particularly, from clients who had been on ART for some time. Speaking from personal experience, one of the male ART clients who had been on ART for more than two years elucidated:

Feeling well again really encourages us to take these drugs but we are just asking the scientists at least to manufacture an injection or a table drug to be taken every 6 months instead of the way we take these drugs every day. We are tired of taking drugs every day, so sometimes you may say let me rest for a few days (male ART user on ARVs for more than two years, clinic based IDI).

These sentiments were reiterated by several other ART users and care givers as can be seen from the following remarks:

Then there is getting tired of taking the drug every day especially when you start feeling well, then you are tempted to stop, you even start thinking to yourself maybe it was not even AIDS after all, so temptations are there (Male ART client on ART for 3 years clinic based IDI).

I can tell you my sister (referring to the researcher), temptations to stop are there because you get tired of taking tablets every day for the rest of your life, more than two years of taking medicines every day is not a joke but when I think about the illness in the past, how sick I was, I tell myself, I have to continue taking these drugs (Male ART user in mid-forties, community based FGD).

Then the taking of medicines every day is also a problem as some people would want to give themselves some days off especially when they start feeling well, my husband sometimes becomes reluctant to take his medication. But I am always on him because I suffered a lot to look after him when he was very sick (Care-giver of a husband who was once bedridden, Community based IDI).

When it is time to take medicines, I start dreading because it is tiring taking medicine every day (middle aged male ART user clinic based male FGD).

Some study participants reported getting used to taking medication every day as having enabled them to adhere to medication, as this had become part of their lives, to an extent that it had become like dressing up in the morning before going for work.

\subsubsection{Non Recovery While on Medication for Some Time}

It was also reported that some people who were on medication for some time but did not experience any improvement in their health were discouraged from continuing with treatment as they saw no reason for doing so. 


\section{Discussions}

This study has established that there were many factors that either positively or negatively influenced a person capacity to adhere to ART medication. Among the identified facilitating factors, consistent with many other studies within the region were having reminders [25] [26]. As can be seen in Table 1, there is a very significant association between one having a reminder and adherence to ART with a $p$-value of $p=0.000$. Other facilitating factors were disclosure of one's status [27]. Disclosure also facilitated adherence because of the possibility of material and emotional support that came with it. However, findings from this study reveal that while disclosure was beneficial for adherence, many people decided not to disclose for fear of HIV and AIDS stigma and other related negative reactions. Non-disclosure of one's HIV positive status due to fears associated with stigma and related outcomes has been alluded to before as one of the biggest challenges in the prevention of HIV and access to HIV and AIDS-related services [26].

Another factor rose in this study and reported to be a facilitator for adherence, a finding that is not unique to Chivuna but to other settings in the region as well [28] [29] was desire to live longer. This factor was reported to be for either personal reason because life was good or for the sake of other people such as one's family particularly for those that had very young children. So because of this desire, those who initiated ART were encouraged to continue taking medicines and be retained in care. This finding is consistent with those of [30]. In this study, the statistical measure for both seeing someone on ART recover and desire to live linger was at $\mathrm{p}$-value $=0.00$. This is an indication of very significant correlation between the two factors and adherence to ART.

As reported by [31] [32] feeling better or healthy again after being on ART was another facilitator for adherence. This is because people did not want a relapse of their illness and wanted to continue looking well, looking after themselves and providing for their families. To some extent, however, in this study, feeling better acted as a barrier because some of those who recovered felt that they had been cured of their disease and so saw no reason of continuing with taking the ARVs.

Desire to live longer, seeing someone on ART recover, and feeling better were linked to the perceived efficacy and positive perceptions of people in this community had about ARVs. So, therefore, because of this, most people knew that to live longer once diagnosed with HIV, one had to take ARVs. Those who were once bed ridden had become healthy and feeling better again because of ARVs.

Some patients, particularly those that had been on medication for a long time, like in other studies [19] [33] [34] complained about drug fatigue. This was worse among patients that showed no recovery after being on medication for a considerable length of time. Consistent with other studies [33], findings from this study show that the longer the duration of treatment, the more adherences will decline. But unlike such earlier studies, this study showed that adherence 
increased with longer duration of treatment.

Fear of side effects was another, a factor linked to the medication. Most clients on ART complained about drug-related adverse side effects such as increased and intolerable hunger and appetite while on ARVs. This was a predictor for treatment interruptions in this resource poor setting where food for some people was hard to find. Though fear of side effects may be a factor even for HIV testing and ART initiation, they were however more frequently mentioned for adherence and this is mainly because, in both testing and ART initiation, the fears would only be anticipated while as in adherence, they were as actually experienced by those taking ARVs. Consistent with findings from other settings, just forgetting [20], forgetting due to being drunk [34], because of being away from home during dosing time or travelling without the medicines [10] and because of being with busy with other chores [34] were also reported in the present study and all contributed to treatment interruptions.

\section{Conclusions}

This study has shown that there exist both facilitating and limiting factors influencing adherence to ART at individual level. Having a reminder has proved to be one of the most important facilitator for adherence. There is need to harness the facilitating factors such as encouraging people on ART to have a reminder either in form of a human being or physical object so as to avoid forgetting especially in the initial stages of treatment. Disclosure was also found to be important for one being reminded and adherence. That is people can only remind if they know about some body's HIV status. Additionally, disclosure was also important because of the material and emotional support that came with it. However, in this study, pervasive HIV and AIDS-related stigma usually discouraged some people from disclosing and hence lost out on the benefit of doing so. This calls for continued community based sensitisation so as to tackle such vices in the community.

Through the use of role models, many people can be able to learn from those who have recovered and become well again due to ARVs so as to see the benefits of ART. This can act as a facilitating factor. Lastly, there is need, through information, education and communication (IEC), to educate people about the issue of side effects and the importance of continuing with their medication even when they feel better so as to avoid treatment interruptions and drug resistance.

\section{Acknowledgements}

This study was part of the ART access project and it was by funded by The Swiss National Science Foundation (SNF) through the Swiss Tropical and Public Health Institute. We acknowledge this funding. We also acknowledge the support from our host institution, the University of Zambia for the space and time to work on this paper. The views expressed in this paper are entirely those of the authors. 


\section{Conflicts of Interest}

The authors declare no conflicts of interest regarding the publication of this paper.

\section{References}

[1] UNAIDS (2010) The Report on the Global AIDS Epidemic.

[2] Fox, M.A., Mazumba, P.D., Seidnberg, I., Crooks, D., Sikateyo, B. and Rosen, S. (2010) Barriers to Initiation of ART in Rural and Urban Areas of Zambia: A Cross-Sectoral Study of Cost, Stigma and Perceptions of ART. Journal of the International AIDS Society, 13, 8. https://doi.org/10.1186/1758-2652-13-8

[3] Munk, K. (1997) Traditional Health; Traditional Hospitals and HIV and AIDS: A Case Study in KwaZulu-Natal. AIDS Analysis Africa, 7, 10-12.

[4] Christofides, N. and Jewkes, R. (2010) Acceptability of Universal Screening for Intimate Partner Violence in Voluntary HIV Testing and Counselling Services in South Africa and Service Implications. AIDS Care, 22, 279-285. https://doi.org/10.1080/09540120903193617

[5] Roura, M., Urassa, M. and Busza, J. (2008) Scaling up Stigma? The Effects of Antiretroviral Roll-Out on Stigma and HIV Testing: Early Evidence from Rural Tanzania, Sex Transmission Infection. https://doi.org/10.1136/sti.2008.033183

[6] Ntalasha, H., Malungo, J.R.S., Merten, S. and Simona, S.J. (2015) The Influence of Food on HIV Testing and Adherence to Treatment in a Resource-Poor Setting, a Case of Chivuna Southern Province. Science Journal of Public Health, 3, 314-320. https://doi.org/10.11648/j.sjph.20150303.13

[7] Ntalasha, H. and Malungo, J.R.S. (2013) Coping Mechanisms to Barriers of Antiretroviral Therapy in a Rural Setting of Zambia: A Case of Chivuna. Zango: Zambian Journal of Contemporary Issues, Vol. 30.

[8] Wu, Z., Zhao, Y., Chunging, L. and Detels, R. (2007) Using Case Vignettes to Measure HIV-Related Stigma among Health Professional in China. International Journal of Epidemiology, 36, 178-184. https://doi.org/10.1093/ije/dyl256

[9] Sandlelowski, M., Lambe, C. and Borroso, J. (2004) Stigma in HIV Positive Women. Journal of Nursing Scholarship, 36, 122-128. https://doi.org/10.1111/j.1547-5069.2004.04024.x

[10] Schuster, M.A., Collins, R., Cunninham, W.E., Morton, S., Zierler, S., Wong, M. and Kanouse, D.E. (2005) Perceived Discrimination in Clinical Care in Nationally Representative Sample of HIV Infected Adults Receiving Health Care. Journal of General Internal Medicine, 20, 807-812. https://doi.org/10.1111/j.1525-1497.2005.05049.x

[11] Bangsberge, D.R.S., et al. (2003) High Levels of Adherence Do Not Prevent Accumulation of HIV Drug Resistance Mutations. AIDS, 17, 1925-1932.

https://doi.org/10.1097/00002030-200309050-00011

[12] Ferro, E.G. and Weikum, D. (2015) Alcohol Use Disorders Negatively Influence Entire Medication Adherence among Men Who Have Sex with Men in Peru. AIDS, 27, 93-104. https://doi.org/10.1080/09540121.2014.963013

[13] Kalichman, S. and Simbayi, L. (2003) HIV Testing Attitudes, AIDS Stigma and Voluntary HIV Counselling and Testing in a Black Township in Capetown, South Africa. Sexually Transmitted Infections, 79, 442-447. https://doi.org/10.1136/sti.79.6.442

[14] Meiberg, A.E., Bos, A.E.R., Onya, H.E. and Schaalma, H.P. (2008) Fear of Stigmati- 
sation as Barrier to Voluntary HIV Counseling and Testing in South Africa. East Africa Journal of Public Health, 5, 49-53.

[15] UNAIDS (2012) The Report on the Global AIDS Epidemic.

[16] Chesney, M., Morin, M. and Sherr, L. (2000) Adherence to HIV Combination Therapy. Social Science and Medicine, 50, 1599-1605. https://doi.org/10.1016/S0277-9536(99)00468-2

[17] Carlucci, J.G., Kamanga, A., Sheneberger, R., Jenkins, C.A., Spurrier, J. and Vermund, S.H. (2008) Predictors of Adherence to ART in Rural Zambia. Journal of Acquired Immune, Deficiency Syndrome, 47, 228-230. https://doi.org/10.1097/QAI.0b013e318165dc25

[18] Chesney, M.A., Hecht, F.M., Sikipa, G. and Rabkin, J. (1999) Adherence: A Necessity for Successful HIV Combination Therapy. TB Clinic Based DOT Model for the Delivery of HAART. AIDS, 13, 5271-5278.

[19] Grant, E., Logre, D., Gorman, D. and Murray, S.A. (2008) Factors Facilitating and Challenging Access and Adherence to Antiretroviral Therapy in a Township in the Zambian Copper-Belt Province: A Qualitative Study. AIDS Care, 20, 1155-1159. https://doi.org/10.1080/09540120701854634

[20] Ministry of Health (2012) Zambia Country Report, Lusaka, Zambia.

[21] Barfod, T.S., Sorensen, H.T., Niesen, H., Rodkjoer, L. and Obel, N. (2006) Simply Forget Is the Most Common Frequently Stated Reason for Missed Doses of HAART Irrespective of Degree ODF Adherence, British HIV Association. HIV Medicine, 7, 285-290. https://doi.org/10.1111/j.1468-1293.2006.00387.x

[22] Schumaker, L.L. and Bond, V. (2008) Antiretroviral Therapy in Zambia: Colours Spoiling Talk and the Meaning of Antiretrovirals. Social Science and Medicine, 67, 2121-2134. https://doi.org/10.1016/j.socscimed.2008.09.006

[23] Hardon, A.P., Akurut, D., Comoro, C., Ekezie, C., Irunde, H.F., Gerrits, T., Kglatwane, J., Kinsman, J., Kwasa, R., Maridadi, J., Moroka, T.M., Moyo, S., Nakiyemba, A., Nsimba, S., Ogenyi, R., Oyabba, T., Temu, F. and Laing, R. (2007) Hunger, Waiting Times and Transport Costs: Time to Confront Challenges to ART Adherence in Africa. AIDS Care, 19, 658-665. https://doi.org/10.1080/09540120701244943

[24] Merten, S., Kenter, E., Mckenzie, O., Musheke, M., Ntalasha, H. and Martin-Hilber, A. (2010) Patient-Reported Barriers and Drivers of Adherence to Antiretrovirals in Sub-Saharan Africa: A Meta-Enthnography. Tropical Medicine and International Health, 15, 1-18. https://doi.org/10.1111/j.1365-3156.2010.02510.x

[25] Murray, L.K., Semrau, E., McCurley, D.M., et al. (2009) Barriers to Acceptance and Adherence of Antiretroviral Therapy in Urban Zambian Women: A Qualitative Study. AIDS Care, 21, 78-86. https://doi.org/10.1080/09540120802032643

[26] Grant, E., Logre, D., Gorman, D. and Murray, S.A. (2008) Factors Facilitating and Challenging Access and Adherence to Antiretroviral Therapy in a Township in the Zambian Copper-Belt Province: A Qualitative Study. AIDS Care, 20, 1155-1159. https://doi.org/10.1080/09540120701854634

[27] Musheke, M., Ntalasha, H., Gari, S., Mckanzie, O., Bond, V., Martin-Hilber, A. and Merten, S. (2013) A Systematic Review of Qualitative Findings on Factors Enabling and Deterring Uptake of HIV Testing in Sub-Saharan Africa. BMC Public Health, 13, 220. https://doi.org/10.1186/1471-2458-13-220

[28] Nuwaha, F., Kabatesi, D., Whalen, C.C. and Muganwa, M. (2002) Factors Influencing Acceptability of Voluntary Counselling and Testing for HIV in Bushenyi District of Uganda. East African Medical Journal, 79, 626-632.

https://doi.org/10.4314/eamj.v79i12.8669 
[29] Unge, C., Johansson, A.R., Zachariah, D. and Engelgem, I.V. (2008) Reasons for Unsatisfactory Acceptance of Antiretroviral Treatment in the Urban Kibera Slum, Kenya. AIDS Care, 20, 146-149. https://doi.org/10.1080/09540120701513677

[30] Ware, N.C., Idoko, J., Kaaya, S., Binaro, I.A., et al. (2009) Explaining Adherence Success in Sub-Saharan Africa: An Ethnographic Study. PLOS Medicine, 6, e11. http://www.plosmedicine.org https://doi.org/10.1371/journal.pmed.1000011

[31] Weiser, S., Wolfe, W., Bangsberge, D.R., Gilbert, P., MaKhema, J., Kebaabetswe, P., Dickenson, D., Kgosidialwa, M. and Marlink, R. (2003) Barriers to Antiretroviral Adherence for Patients Living with HIV Infection and AIDS in Botswana. Journal of Acquired Immune Deficiency Syndromes, 34, 281-288. https://doi.org/10.1097/00126334-200311010-00004

[32] WHO (2013) Consolidated Guidelines on the Use of Antiretroviral Drugs for Treatment and Prevention of HIV Infection: Recommendation for a Public Approach. Geneva.

[33] Nachega, J.B., Knowlton, A.R., Deluca, A., Schoeman, J.H., Watkinson, L., Efron, A., Chaisson, R.E. and Maartens, G. (2006) Adherence to Antiretroviral Therapy in HIV Infected South African Adults, Stigma, Alcohol Abuse, Lack of Financial Resources and Food and Treatment Supporters to Improve Adherence. Acquired Immune Deficiency Syndrome, 43, 5127-5132. https://doi.org/10.1097/01.qai.0000248349.25630.3d

[34] Layer, E.H., Kennedy, C.E., Beckham, S.W., Mbwambo, J.K., Likindikoki, S., et al. (2014) Multi-Level Factors Affecting Entry into and Engagement in the HIV Continuum of Care in Iringa, Tanzania. PLOS ONE, 9, e104961.

https://doi.org/10.1371/journal.pone.0104961 